\title{
PEMODELAN SPASIAL BAHAYA LONGSOR DI DAS CILIWUNG HULU, KABUPATEN BOGOR
}

\author{
Muhamad Rizal Gojali ${ }^{1)}$ Boedi Tjahjono ${ }^{2 \#)}$ Ernan Rustiadi2\#) \\ 1,2\#)Program Studi Ilmu Tanah dan Sumberdaya Lahan, Fakultas Pertaninan, \\ Institut Pertanian Bogor, Bogor, Indonesia \\ \#Corresponding Author: boedi tj@yahoo.com ernan@indo.net
}

Article history: received 5 December 2019; revised 16 January 2020; accepted 25 January 2020

\begin{abstract}
Abstrak
Longsor merupakan fenomena alam yang terjadi karena alam mencari keseimbangan akibat adanya gangguan yang mempengaruhi lahan pada titik longsor tersebut. Kabupaten Bogor dikategorikan ke dalam zona rawan gerakan tanah tingkat menengah sampai tinggi oleh BNPB, dalam hal ini DAS Cilwung Hulu merupakan wilayah yang sering mengalami longsor. Penelitian ini bertujuan untuk membangun model spasial bahaya longsor di DAS Ciliwung Hulu dengan metode penilaian berbasis PCA dari faktor-faktor penyebab longsor. Hasil penelitian menunjukkan bahwa terdapat tujuh parameter yang dapat digunakan untuk pemodelan spasial bahaya longsor, yaitu bentuklahan, penggunaan lahan, kemiringan lereng, curah hujan, kelurusan, jenis tanah, dan litologi. Berdasarkan hasil analisis didapatkan bahwa bobot masingmasing parameter secara berurutan adalah 0,347; 0,223; 0,200; 0,100; 0,071; 0,049; dan 0,010. Dalam hal ini bentuklahan mempunyai bobot tertinggi sebagai penentu bahaya longsor. Luas kelas bahaya longsor (rendah, sedang, dan tinggi) yang diperoleh dari hasil pemodelan berturutturut adalah 4.651,53 ha (31\%), 6.637,72 ha (43\%), dan 3.941,41 ha (26\%) dengan akurasi keseluruhan sebesar 57,8 .
\end{abstract}

Kata kunci: bahaya longsor, Bogor, DAS Ciliwung Hulu, model spasial, PCA

\begin{abstract}
Landslide is a natural phenomenon that occurs because nature is looking for a balance due to disturbance affecting the land at the point of the landslide. Bogor Regency is categorized into a medium to high level ground vulnerable zone by BNPB, in this case the Cilwung Hulu watershed is an area that often experiences landslides. This study aims to develop a spatial model of landslides in the Ciliwung Hulu watershed using a PCA-based assessment method of the factors causing landslides. The results showed that there are seven parameters that can be used for spatial modeling of landslides, namely landform, land use, slope, rainfall, straightness, soil type, and lithology. Based on the results of the analysis it was found that the weight of each parameter is $0.347 ; 0.223 ; 0,200 ; 0,100 ; 0.071 ; 0.049$; and 0.010. In this case landform has the highest weight as a determinant of landslide hazards. The area of landslide hazard class (low, medium, and high) obtained from the results of modeling are 4,651.53 ha (31\%), 6,637.72 ha (43\%), and $3,941.41$ ha (26\%) with accuracy overall of 57.8 .
\end{abstract}

Keywords: landslide hazard, Bogor, Ciliwung Hulu watershed, spatial model, PCA

\section{Pendahuluan}

Indonesia terletak pada wilayah pertemuan antara tiga lempeng besar aktif dunia, yaitu Eurasia, Pasifik, dan Indo-Australia serta satu lempeng mikro yaitu lempeng Filipina [1]. Pergerakan lempeng menyebabkan terbentuknya bentuklahan di Indonesia yang bervariasi mulai dari pegunungan, perbukitan, hingga dataran di pesisir pantai. Selain menghasilkan keragaman bentuklahan, pergerakan lempeng juga melahirkan bencana alam yang merusak, seperti 
gempabumi, letusan gunungapi, tsunami, dan gerakan tanah (longsor). Sungguh pun demikian faktor manusia juga mempunyai pengaruh besar sebagai pemicu terjadinya bencana, seperti longsor, pencemaran lingkungan, dan degradasi lahan akibat ketidaksesuaian antara daya dukung lahan dengan peruntukannya. Saat ini, kejadian bencana longsor di Indonesia mempunyai kecenderungan yang semakin meningkat begitu pula dengan sebaran wilayah bencana yang semakin luas [2].

Longsor adalah fenomena alam dimana alam mencari keseimbangan baru akibat adanya gangguan pada lahan [3]. Provinsi Jawa Barat termasuk salah satu daerah yang memiliki potensi tinggi untuk terjadinya bencana longsor. Hal ini disebabkan oleh bentuklahan wilayahnya yang banyak berelief perbukitan dan pegunungan serta kepadatan penduduk yang tinggi, sehingga tekanan terhadap lingkungan pun meningkat. Kawasan rawan longsor Provinsi Jawa Barat terdapat di beberapa kabupaten, di antaranya adalah di Bandung, Cianjur, Bogor, Sukabumi, Majalengka, Sumedang, Ciamis, Tasikmalaya, Kuningan, dan Purwakarta. Berdasarkan peta zona bahaya gerakan tanah Provinsi Jawa Barat skala 1:250.000 [4], Kabupaten Bogor dikategorikan ke dalam zona gerakan tanah kelas menengah sampai tinggi [4], dimana DAS Cilwung Hulu merupakan wilayah Kabupaten Bogor yang sering mengalami longsor.

Beberapa penelitian terkait longsor pernah dilakukan di DAS Ciliwung Hulu [5, 6] baik yang menyangkut kerawanan maupun bahaya dan risiko longsor di DAS Ciliwung Hulu kemudian dikaitkan dengan persebaran permukiman dan penataan ruang. Penelitian di atas menggunakan metode pembobotan dan skor dari institusi pemerintah, dan dicoba pula membangun parameter baru yang agak berbeda dari pemerintah [5]. Penelitian kali ini berbeda pendekatannya dengan penelitian sebelumnya tersebut, yakni menggunakan metode Principal Component Analysis (PCA), menggunakan tujuh parameter, dan hasilnya divalidasi dengan titik-titik longsor yang pernah terjadi di lapangan. Diharapkan melalui pendekatan kuantitatif ini hasilnya bisa menggambarkan kondisi aktual di lapangan karena kejadian longsor di masa lalu merupakan indikasi terhadap kondisi masa depan, apalagi karakteristik lingkungan, seperti topografi, litologi, hidrologi, dan tutupan/penggunaan lahan masih relatif sama [7]. Sungguh pun demikian pendekatan universal yang cocok untuk semua wilayah belum ada karena keandalan model tergantung terutama pada kualitas data yang tersedia di wilayah tersebut dan pada model yang diterapkan [8].

Seperti diketahui penyebab longsor cukup beragam, namun yang berasal dari alam meliputi bentuk permukaan bumi (landform), penggunaan lahan, litologi, struktur geologi, curah hujan, dan kegempaan; dari faktor manusia antara lain meliputi kegiatan pertanian, pembebanan lereng, pemotongan lereng, dan penambangan; dan dari faktor manajemen sumberdaya lahan antara lain berupa penggunaan lahan, infrastruktur, dan kepadatan permukiman [9]. Dalam hal ini aktivitas manusia yang membebani lereng tidak dapat diabaikan kontribusinya karena aktivitasnya cukup dinamik [10]. Dalam pembangunan nasional peta bahaya bencana, seperti bahaya longsor, sangat lah diperlukan guna mendukung perencanaan pembangunan yang lebih baik. Namun demikian peta-peta bahaya bencana dalam skala besar masih sedikit bisa didapatkan di tanah air. Oleh karena itu penelitian ini bertujuan untuk membangun model pemetaan bahaya longsor skala menengah dan mengambil lokasi di DAS Ciliwung Hulu, Kabupaten Bogor.

\section{Metode Penelitian}

Dalam penelitian ini untuk membangun pemodelan bahaya longsor dengan pendekatan metode Principal Component Analysis (PCA) dilakukan dalam tiga tahapan, yaitu (1) pengumpulan data, (2) analisis data (penentuan skor, analisis korelasi antar faktor, pembobotan, penilaian bahaya longsor), dan (3) validasi model.

Pengumpulan data meliputi pencarian data titik kejadian longsor dari instansi atau literatur (data sekunder) maupun survei lapangan (data primer). Data titik longsor yang terkumpul selanjutnya akan digunakan untuk menilai kepadatan titik longsor di wilayah penelitian dengan ukuran $5 \mathrm{~km}$ x $5 \mathrm{~km}$ [7]. Data yang dikumpulkan meliputi 7 faktor penyebab longsor, yaitu penggunaan lahan, litologi, jenis tanah, bentuklahan, kemiringan lereng, kelurusan, dan curah hujan.

Penentuan skor dari masing-masing faktor dilakukan melalui analisis regresi, yaitu antara faktor penyebab longsor dengan kejadian longsor. Analisis regresi yang digunakan meliputi trend linear dan polynomial. Nilai koefisien determinasi hasil regresi yang tinggi digunakan untuk 
KOMPUTASI (Jurnal IImiah IImu Komputer dan Matematika)

Vol. 17, No. 1, Januari 2020, Hal. $311-318$

P-ISSN: 1693-7554, E-ISSN: 2654-3990

https://journal.unpak.ac.id/index.php/komputasi

menghitung skor dugaan. Tujuan dari tahap ini adalah untuk menentukan peringkat dan signifikansi pengaruh sub-faktor terhadap kejadian longsor serta menentukan penghitungan kembali untuk semua sub-faktor yang dianalisis. Metode penghitungan kembali sub-faktor menggunakan rumusan yang disajikan pada Persamaan 1 [8].

$$
\begin{array}{ll}
\text { Score } R_{\text {out }}=\left[\left(\frac{\text { Score } E_{\text {input }}-\text { Score } E_{\min }}{\text { Score } E_{\max }-\text { Score } E_{\min }}\right) *\left(\text { Score } R_{\max }-\text { Score } R_{\min }\right)\right]+\text { Score } R_{\min } \\
\text { Keterangan : } & \text { Nilai skor hasil rescalling } \\
\text { Score Rout } & =\text { Nilai skor dugaan }(\text { expected score }) \text { input } \\
\text { Score } E_{\text {input }} & =\text { Nilai minimal skor dugaan } \\
\text { Score } E_{\min } & =\text { Nilai maksimal skor dugaan } \\
\text { Score } E_{\max } & =\text { Nilai skor tertinggi hasil rescalling } \\
\text { Score } R_{\max } & =\text { Nilai skor terendah hasil rescalling }
\end{array}
$$

Dalam penentuan bobot dilakukan terhadap faktor-faktor yang dianalisis, dimana bobot mencerminkan peringkat kontribusi terhadap kejadian longsor di wilayah penelitian. Analisis penentuan bobot dilakukan dengan menggunakan pendekatan Principal Component Analysis atau PCA [7 dan 9] dengan menggunakan perangkat lunak statistik SPSS. Analisis PCA selanjutnya menghasilkan komponen utama yang menjelaskan besaran komponen dari faktorfaktor yang dianalisis. Dalam hal ini bobot dari masing-masing faktor dihasilkan dari komposit yang mengalikan antara nilai pemuatan komponen dengan persentase varians dari masingmasing besaran utama [10], seperti yang digambarkan dalam Persamaan 2.

Keterangan:

$$
W_{i}=\sqrt{\sum_{i j=1}^{n} V_{i j}^{2} P_{i j}}
$$

$\mathrm{W}_{\mathrm{i}}=$ Bobot faktor ke- $\mathrm{i}$

$\mathrm{V}_{\mathrm{ij}}=$ Komponen Utama (component loading) i ke j

$\mathrm{P}_{\mathrm{ij}}=$ Persen varians $\mathrm{i}$ ke $\mathrm{j}$

Penilaian bahaya longsor dalam penelitian ini diambil dari rumus Landslide Susceptibility Index atau LSI [10], dimana nilai LSI secara teknis diklasfikasikan ke dalam rentang bahaya sangat rendah sampai bahaya sangat tinggi dengan menggunakan ArcGis 10.3 melalui Persamaan 3 [11] dan kemudian divisualisasikan ke dalam bentuk peta bahaya longsor.

$$
\mathrm{LSI}=\sqrt{\sum_{i=1}^{n} \operatorname{Score}_{i} * W_{i}}
$$

$$
\begin{aligned}
& \text { Keterangan: } \\
& \begin{array}{ll}
\text { LSI = Indeks Bahaya Longsor } \\
\text { Score }_{i}=\text { Skor rescalling sub faktor ke-i } \\
\mathrm{W}_{\mathrm{i}}=\text { Bobot faktor ke-i }
\end{array}
\end{aligned}
$$

Untuk validasi, Akurasi Keseluruhan atau Overall Accuracy (OA) dipilih untuk validasi model, yaitu dengan membandingkan antara kepadatan longsor aktual dengan kelas bahaya longsor. Akurasi dalam hal ini menggambarkan model mana yang paling match terhadap kepadatan titik longsor seperti yang digambarkan dalam Persamaan 4. 


$$
O A=\left(\frac{\sum_{i=1}^{n} X i i}{N}\right) * 100 \%
$$

Keterangan:

$\mathrm{OA}=$ Overall Accuracy (akurasi keseluruhan)

$\mathrm{X}_{\mathrm{ii}} \quad=$ Jumlah kolom ke-1 dan baris ke-1

$\mathrm{N} \quad=$ Jumlah semua kolom dan semua baris yang digunakan

\section{Hasil dan Pembahasan}

Bahaya (hazard) adalah suatu ancaman peristiwa alam yang bersifat ekstrim dan dapat berakibat buruk atau tidak menyenangkan [15] seperti halnya peristiwa longsor. Adapun pemodelan bahaya longsor adalah suatu upaya untuk memprediksi kejadian longsor yang dapat terjadi di waktu yang akan datang atau dalam waktu dekat. Salah satu metode yang dapat digunakan untuk pemodelan spasial adalah Principal Component Analysis (PCA) seperti yang dilakukan dalam penelitian ini. Faktor-faktor penyebab longsor yang dipertimbangkan meliputi penggunaan lahan, litologi, jenis tanah, bentuklahan, kemiringan lereng, kelurusan, dan curah hujan. Gambaran spasial dari masing-masing faktor tersebut disajikan pada Gambar 1

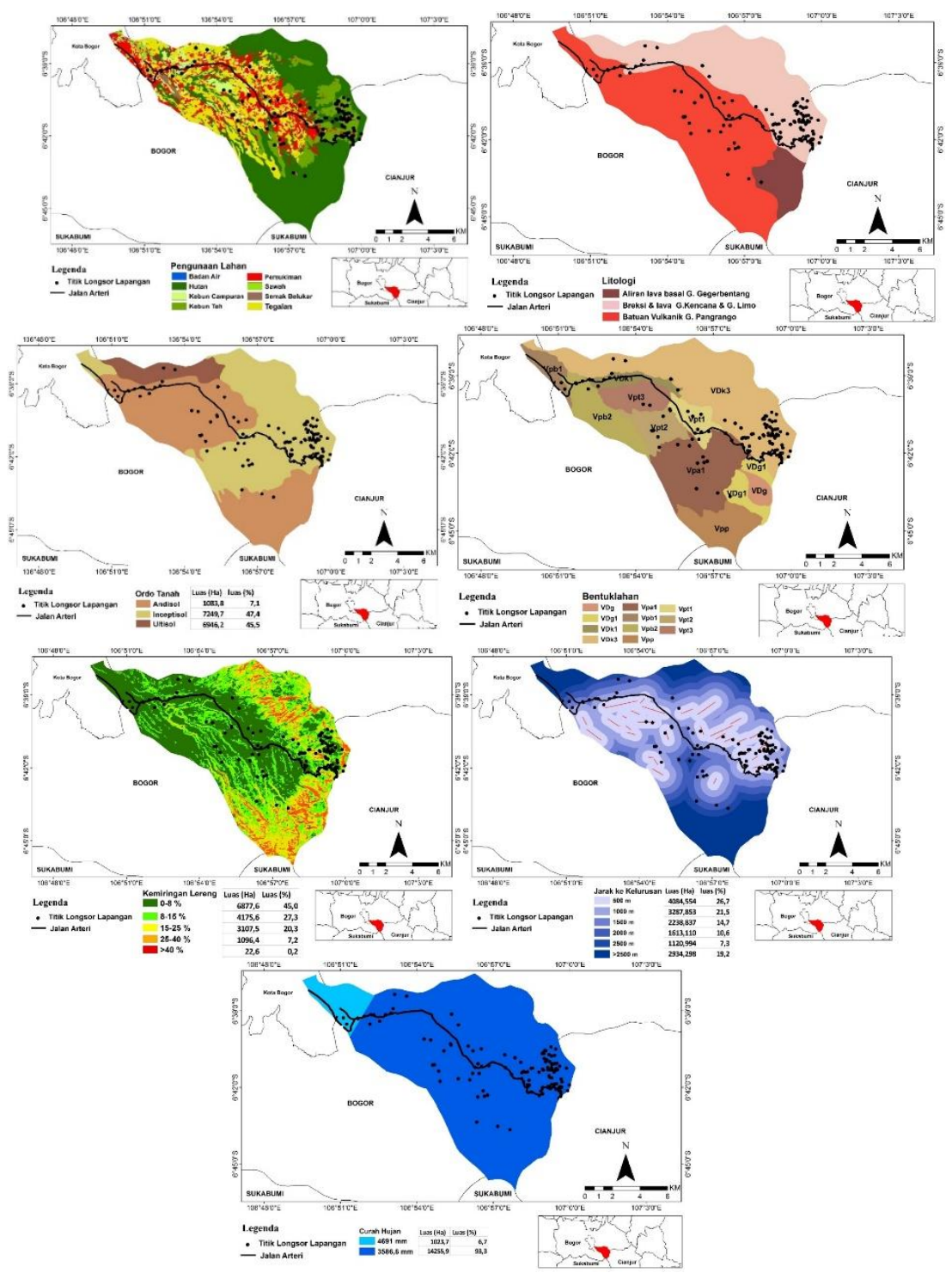


KOMPUTASI (Jurnal IImiah IImu Komputer dan Matematika)

Vol. 17, No. 1, Januari 2020, Hal. $311-318$

P-ISSN: 1693-7554, E-ISSN: 2654-3990

https://journal.unpak.ac.id/index.php/komputasi

Gambar 1. Gambaran spasial faktor-faktor penentu longsor di DAS Ciliwung Hulu

Dengan metode PCA ini, perhitungan skor (rescaled score) menggunakan Persamaan 1 dan hasilnya kemudian di-overlay-kan dengan kejadian titik-titik longsor yang ada di lokasi penelitian. Hasil overlay selanjutnya digunakan untuk analisis korelasi serta penetuan bobot dalam pemodelan. Dalam hal ini analisis korelasi bertujuan untuk melihat hubungan antara faktor yang satu dengan yang lain. Jika nilai korelasi signifikan antar faktor tinggi, maka faktor tersebut dikelompokkan sebagai faktor umum yang bisa mewakili faktor lainnya (karena mempunyai nilai sama). Jadi hasil analisis ini dimaksudkan untuk mencegah terjadinya redundansi dan multikoliniearitas antar faktor. Hasil analisis korelasi yang didapat dari penelitian ini menujukkan angka sebesar $<0,60$ dari masing-masing faktor (Tabel 1), sehingga tidak ada faktor yang dikelompokkan menjadi faktor umum.

Tabel 1. Nilai korelasi antar faktor

\begin{tabular}{lccccccc}
\hline \multirow{1}{*}{ Faktor } & \multicolumn{7}{c}{ Correlation Matrix } \\
\cline { 2 - 8 } & Litologi & Lereng & $\begin{array}{c}\text { Bentuk } \\
\text { lahan }\end{array}$ & $\begin{array}{c}\text { Jenis } \\
\text { Tanah }\end{array}$ & $\mathrm{PL}$ & $\begin{array}{c}\text { Curah } \\
\text { Hujan }\end{array}$ & Kelurusan \\
\hline Litologi & 1,000 & 0,178 & $-0,366$ & $-0,485$ & $-0,052$ & $-0,271$ & $-0,564$ \\
Lereng & 0,178 & 1,000 & $-0,045$ & $-0,079$ & 0,181 & $-0,004$ & $-0,089$ \\
Bentuklahan & $-0,366$ & $-0,045$ & 1,000 & 0,106 & 0,108 & 0,366 & 0,275 \\
Jenis Tanah & $-0,485$ & $-0,079$ & 0,106 & 1,000 & 0,308 & 0,299 & 0,434 \\
$\begin{array}{l}\text { Penggunaan } \\
\text { Lahan }\end{array}$ & & & & & & \\
Curah Hujan & $-0,052$ & 0,181 & 0,108 & 0,308 & 1,000 & 0,001 & 0,106 \\
Kelurusan & $-0,271$ & $-0,004$ & 0,366 & 0,299 & 0,001 & 1,000 & 0,367 \\
\hline
\end{tabular}

Untuk penilaian bobot terhadap masing-masing faktor selanjutnya menggunakan Persamaan 2 . Bobot ini dianalisis dengan tujuan untuk mendapatkan model terbaik yang akan dipakai untuk penentuan model spasial. Masing-masing bobot yang dihasilkan kemudian diuji agar dapat diketahui komposisi mana yang mampu menjelaskan kejadian longsor. Dari hasil pembobotan (Tabel 2) dapat diketahui ada 6 model yang memiliki bobot bervariasi yang berpengaruh terhadap longsor.

Tabel 2. Bobot faktor hasil analisis PCA

\begin{tabular}{lllllll}
\hline Faktor & PC 1-2 & PC 1-3 & PC 1-4 & PC 1-5 & PC 1-6 & PC 1-7 \\
\hline Litologi & 0,197 & 0,140 & 0,010 & 0,016 & 0,019 & 0,020 \\
Lereng & 0,103 & 0,136 & 0,200 & 0,199 & 0,193 & 0,192 \\
Bentuklahan & 0,096 & 0,171 & 0,347 & 0,337 & 0,326 & 0,325 \\
Jenis Tanah & 0,163 & 0,167 & 0,049 & 0,049 & 0,056 & 0,057 \\
Penggunaan & & & & & & \\
Lahan & 0,141 & 0,106 & 0,223 & 0,218 & 0,213 & 0,216 \\
Curah Hujan & 0,115 & 0,153 & 0,100 & 0,109 & 0,105 & 0,105 \\
Kelurusan & 0,186 & 0,126 & 0,071 & 0,072 & 0,088 & 0,087 \\
\hline
\end{tabular}

Untuk mendapatkan nilai indeks bahaya longsor selanjutnya dugunakan Persamaan 3 yang dihitung dengan mengalikan semua skor (dari masing-masing sub-faktor) dengan bobot faktor. Dalam hal ini skor sub-faktor yang dipakai adalah yang berasal dari hasil rescaled score, sedangkan bobot faktor yang dipakai adalah yang berasal dari hasil analisis komponen utama PCA. Hasil penilaian indeks bahaya longsor yang diperoleh disajikan pada Tabel 3 dan 4 . Pembagian kelas bahaya longsor pada penelitan ini menggunakan metode natural breaks dan memanfaatkan aplikasi ArcGis 10.3. Metode natural breaks adalah metode yang mengelompokkan pola data dengan nilai kelas yang ditentukan berdasarkan jangkauan terbesarnya. Pembagian jumlah kelas bahaya dalam penelitian ini dibagi menjadi 3 dan 5 kelas, 
dimana untuk 5 kelas adalah sangat rendah, rendah, sedang, tinggi, dan sangat tinggi (Tabel 3), sedangkan untuk 3 kelas terbagi menjadi kelas rendah, sedang, dan tinggi (Tabel 4).

Tabel 3. Kelas bahaya longsor

\begin{tabular}{lcccccc}
\hline \multicolumn{1}{c}{ Kelas Bahaya } & PC 1-2 & PC 1-3 & PC 1-4 & PC 1-5 & PC 1-6 & PC 1-7 \\
\hline sangat rendah & $20-39$ & $20-42$ & $20-48$ & $20-48$ & $20-42$ & $20-47$ \\
rendah & $39-54$ & $42-55$ & $48-64$ & $48-63$ & $42-55$ & $47-63$ \\
sedang & $54-66$ & $55-66$ & $64-75$ & $63-75$ & $55-67$ & $63-74$ \\
tinggi & $66-77$ & $66-77$ & $75-86$ & $75-85$ & $67-77$ & $74-85$ \\
sangat tinggi & $77-100$ & $77-100$ & $86-100$ & $85-100$ & $77-100$ & $85-100$ \\
\hline
\end{tabular}

Tabel 4. Kelas bahaya longsor untuk 3 kelas

\begin{tabular}{lcccccc}
\hline \multicolumn{1}{c}{ Kelas Bahaya } & PC 1-2 & PC 1-3 & PC 1-4 & PC 1-5 & PC 1-6 & PC 1-7 \\
\hline rendah & $<50$ & $<53$ & $<51$ & $<55$ & $<54$ & $<51$ \\
sedang & $50-68$ & $53-68$ & $51-65$ & $55-66$ & $54-64$ & $51-68$ \\
tinggi & $>68$ & $>68$ & $>65$ & $>66$ & $>64$ & $>68$ \\
\hline
\end{tabular}

Untuk penilain overall accuracy digunakan Persamaan 4 yang diaplikasikan pada kelas bahaya longsor, baik yang 5 kelas maupun 3 kelas. Dalam Tabel 5 terlihat bahwa model 2 (PC 1-3) dalam 5 kelas bahaya longsor memiliki nilai akurasi yang tinggi, yaitu sebesar $39,2 \%$. Sementara itu, untuk 3 kelas bahaya longsor, model 3 (PC 1-4) memiliki nilai akurasi paling tinggi, yaitu sebesar $57,8 \%$ (Tabel 6). Dari angka-angka tersebut di atas, akurasi dari 3 kelas bahaya longsor mempunyai nilai lebih tinggi dibandingkan dengan 5 kelas bahaya longsor.

Tabel 5. Kelas bahaya longsor dengan 5 kelas

\begin{tabular}{lcccccc}
\hline \multicolumn{1}{c}{ Kelas Bahaya } & PC 1-2 & PC 1-3 & PC 1-4 & PC 1-5 & PC 1-6 & PC 1-7 \\
\hline sangat rendah & $20-39$ & $20-42$ & $20-48$ & $20-48$ & $20-42$ & $20-47$ \\
rendah & $39-54$ & $42-55$ & $48-64$ & $48-63$ & $42-55$ & $47-63$ \\
sedang & $54-66$ & $55-66$ & $64-75$ & $63-75$ & $55-67$ & $63-74$ \\
tinggi & $66-77$ & $66-77$ & $75-86$ & $75-85$ & $67-77$ & $74-85$ \\
sangat tinggi & $77-100$ & $77-100$ & $86-100$ & $85-100$ & $77-100$ & $85-100$ \\
\hline Overall acuraccy (\%) & 37,6 & $\mathbf{3 9 , 2}$ & 35,6 & 35,6 & 35,9 & 35,9 \\
\hline
\end{tabular}

Tabel 6. Kelas bahaya longsor dengan 3 kelas

\begin{tabular}{lcccccc}
\hline \multicolumn{1}{c}{ Kelas Bahaya } & PC 1-2 & PC 1-3 & PC 1-4 & PC 1-5 & PC 1-6 & PC 1-7 \\
\hline rendah & $<50$ & $<53$ & $<51$ & $<55$ & $<54$ & $<51$ \\
sedang & $50-68$ & $53-68$ & $51-65$ & $55-66$ & $54-64$ & $51-68$ \\
tinggi & $>68$ & $>68$ & $>65$ & $>66$ & $>64$ & $>68$ \\
\hline Overall acuraccy $(\%)$ & 52,2 & 51,3 & $\mathbf{5 7 , 8}$ & 56,8 & 57,1 & 57,1 \\
\hline
\end{tabular}

Dari hasil di atas, model spasial bahaya longsor yang dipakai dalam penelitian ini adalah yang mempunyai nilai akurasi tertinggi $(57,8)$ dan nilai LSI yang dihitung adalah sebagai berikut:

$$
\begin{gathered}
\text { LSI }=0,347(\text { bentuklahan })+0,223(\text { penggunaan lahan })+0,200(\text { kemiringan lereng }) \\
+0,100(\text { curah hujan })+0,071(\text { kelurusan })+0,049(\text { jenis tanah }) \\
+0,010(\text { litologi })
\end{gathered}
$$


Makna dari model tersebut, berdasarkan bobotnya, adalah bahwa bentuklahan merupakan faktor utama yang mendorong terjadinya longsor di lokasi penelitian dibandingkan dengan faktorfaktor lainnya, sedangkan faktor kedua adalah penggunaan lahan. Dengan kata lain dapat disimpulkan bahwa jika penggunaan lahan yang diterapkan di lokasi penelitian tidak sesuai dengan karakterisitik bentuklahannya, maka penggunaan lahan tersebut akan memicu terjadinya longsor di daerah tersebut.

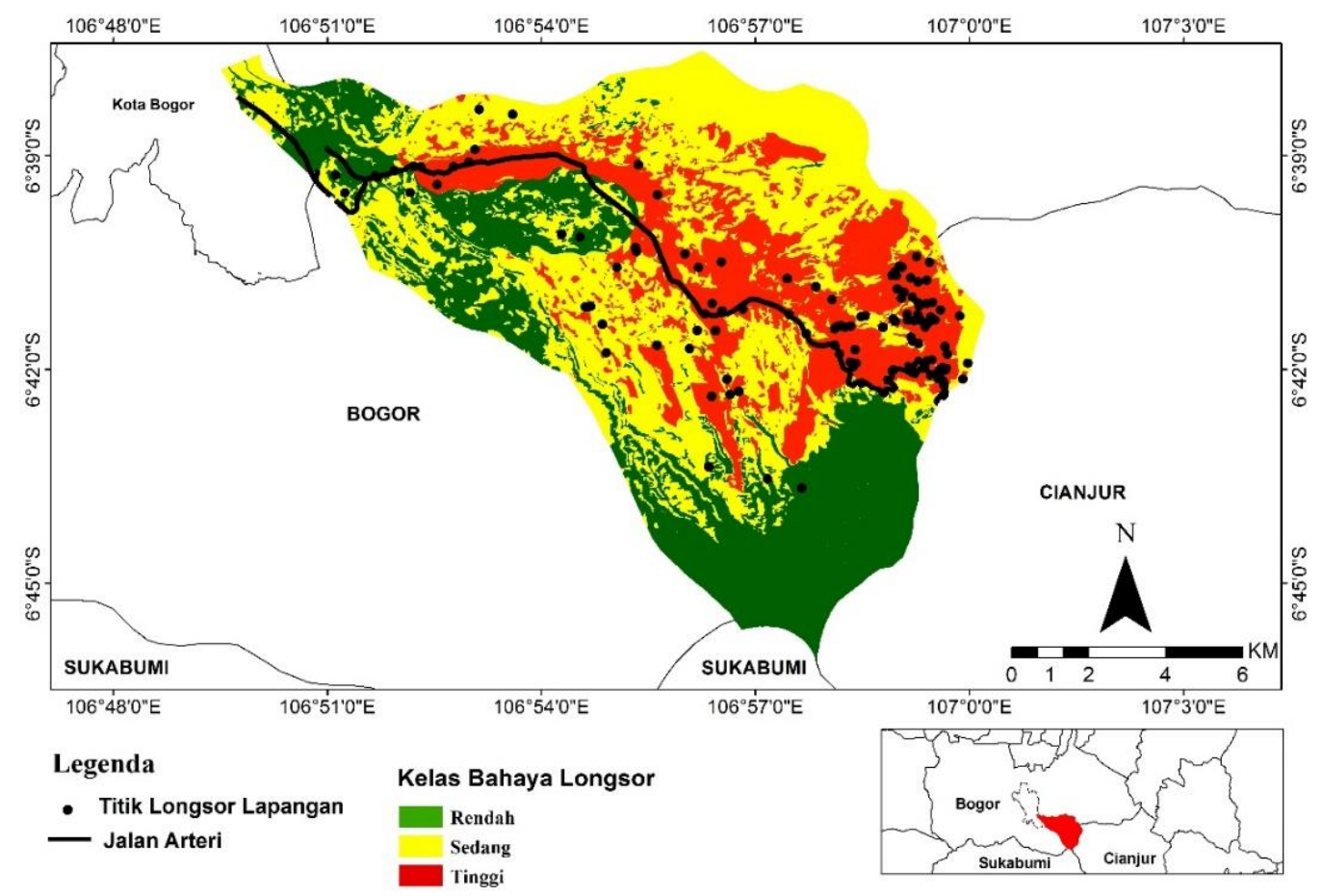

Gambar 1. Peta kelas bahaya longsor

Dari pemodelan bahaya longsor yang dipakai di atas, secara spasial hasilnya dapat disajikan seperti pada Gambar 1 dan dari gambar tersebut dapat diketahui bahwa:

- Kelas bahaya longsor rendah di DAS Ciliwung Hulu mempunyai luas 4.691,55 ha atau $30,72 \%$ dari luas total lokasi penelitian,

- Kelas bahaya longsor sedang di DAS Ciliwung Hulu mempunyai luas 6.637,92 atau $43,47 \%$ dari luas total lokasi penelitian

- Kelas bahaya longsor tinggi di DAS Ciliwung Hulu mempunyai luas 3.941,53 ha atau $25,81 \%$ dari luas total lokasi penelitian.

\section{Kesimpulan}

Berdasarkan model yang diperoleh, penerapan penggunaan lahan di DAS Ciliwung Hulu harus memperhatikan karakteristik bentuklahan (landform) sebagai faktor penentu longsor terbesar, jika hal tersebut terabaikan maka dapat memicu terjadinya longsor di waktu yang akan datang. Pelaksanaan mitigasi perlu dilakukan dengan seksama dan diutamakan untuk wilayah yang memiliki kelas bahaya longsor tinggi dan sedang.

\section{Referensi}

[1] Pasa G dan Tanauma A. 2011. Pemodelan sumber gempa di Wilayah Sulawesi Utara sebagai upaya mitigasi bencana gempa bumi. Jurnal IImu Saims. 11(2).

[2] Amri MR, Yulianti G, Yunus R, Wiguna S, Asi AW, Ichwana AN, Randongir RE, Septian RT. 2018. Risiko Bencana Indonesia. Jakarta (ID): BNPB. 
[3] Widodo A, Machus danTatas. 2011. Studi Investigasi Longsor di Desa Kalikuning Kecamatan Tulakan Kabupaten Pacitan. Jurnal Aplikasi Teknik Sipil. 9(1).

[4] [PVMBG] Pusat Vulkanologi dan Mitigasi Bencana Geologi. 2006. Prakiraan Potensi Longsor di Jawa Barat. Internet: http://www. portal.vsi.esdm.go.id (diakses 25 Juli 2019).

[5] Silviani, R.V. 2013. Analisis bahaya dan risiko longsor di DAS Ciliwung Hulu dan keterkaitannya dengan penataan ruang. [Tesis]. Bogor. Institut Pertanian Bogor.

[6] Dewi I.K. dan F. Abdi (2017). Evaluasi Kerawanan Bencana Tanah Longsor Di Kawasan Permukiman Di Daerah Aliran Sungai (Das) Ciliwung Hulu. [Prosiding]. Seminar Nasional Perencanaan Pembangunan Inklusif Desa Kota. Program Pascasarjana, Universitas Andalas, Padang.

[7] Sabokbar H.F., M. S. Roodposhti, E. Tazik. 2014. Landslide Susceptibility Mapping Using Geographically-Weighted Principal Component Analysis. Geomorphology: 226: 15-24.

[8] Chen G., X. Meng, L. Tan, F. Zhang, L. Qiao. 2014. Comparison and Combination of Different Models for Optimal Landslide Susceptibility Zonation. Quarterly Journal of Engineering Geology and Hydrogeology. 47: 283-306

[9] Paimin, Sukresno, dan Pramono IB. 2009. Teknik Mitigasi Banjir dan Tanah Longsor. Balikpapan (ID). Tropenbos International Indonesia Programme.

[10] Rahman MW, Purwanto MYJ dan Suprihatin. 2014. Status kualitas air dan upaya konservasi sumberdaya lahan di DAS Citarum Hulu, Kabupaten Bandung. Jurnal Pengelolaan Sumberdaya Alam Dan Lingkungan. 4(1): 24-34.

[11] Gunadi DSA. 2017. Spatial modeling of landslide susceptibility (Case Study in West Java Province, Indonesia). [Tesis]. Bogor (ID): IPB University.

[12] Jaya, I.N.S., Purnama, E.S., Arianti, I., Boonyanuphap, J. (2007, May 13-19). Forest Fire Risk Assessment Model and Post-Fire Evaluation Using Remote Sensing and GIS: A Case Study in Riau, West Kalimantan and East Kalimantan Provinces, Indonesia. The Forest Restoration and Rehabilitating Training Course and Workshop in The Viiki Tropical Resources Institute (VITRI) of the University of Helsinki, Finland.

[13] Behestizadeh, H., Rezaie, A., Rezaie, A., Ghandi, A. 2013. Principal component analysis and determination of the selection criteria in bread wheat (Triticum aestivum L.) genotypes. IntI J Agri Crop Sci. 5 (18): 2024-2027.

[14] Gunadi, D.S.A., Jaya, I.N.S., Tjahjono, B. 2017. Spatial Modeling in Landslide Susceptibility. Indonesian Journal of Electrical Engineering and Computer Science. 5 (1): 139-146.

[15] Noor, D. 2014. Pengantar Mitigasi Bencana Geologi. Yogyakarta. Budi Utama. 